\title{
Perfil do Aluno e Aprendizagens Essenciais nas planificações curriculares - componentes do currículo visto pelos formandos
}

\section{Clarinda Barata}

ESECS, CI\&DEI, Politénico de Leiria, Portugal, clarinda.barata@ipleiria.pt.

Resumo
Em Portugal, com as alterações decorrentes da publicação do normativo
legal Decreto-lei $n^{\circ}{ }^{\circ} 55 / 2018$ de 06 de julho que estabelece o currículo dos
ensinos básico e secundário e os princípios orientadores da avaliação das
aprendizagens, com efeitos de aplicabilidade imediata, bem como de
diversos documentos, nomeadamente: "Perfil dos Alunos à Saída da Escolaridade Obrigatória”; das "Aprendizagens Essenciais" dos ensinos básico e secundário, onde se subentende a adoção de práticas letivas distintas das vigentes até então.

O timing da publicação de alguns destes documentos, especificamente, os normativos legais (fim do ano letivo em que o corpo docente estava prestes a entrar de férias) fez com que a grande maioria não se tivesse apropriado da nova filosofia/ideologia e empreendesse num caminho pouco seguro e sem formação específica para o efeito, no ano letivo anterior.

Assim, surgiu a necessidade de criar uma oficina de formação no ano letivo 2019/2020, com o intuito de ajudar os formandos/docentes a: compreender as formas de articular o Perfil do Aluno (PA) com as Aprendizagens Essenciais (AE) e o Currículo; compreender as implicações práticas da articulação proveniente do PA com as AE e o Currículo; problematizar as potencialidades da planificação interdisciplinar como forma de fomentar práticas inclusivas; e, fomentar o desenvolvimento de práticas pedagógicas interdisciplinares através de práticas colaborativas entre professores.

O estudo assume-se como um estudo de caso. Aplicou-se uma questão diagnóstico, na primeira sessão de trabalho presencial, com o intuito de perceber as conceções dos formandos/docentes sobre as componentes do currículo. Para este grupo de formandos o currículo é um conjunto de saberes acabados e universais a transmitir a todos, sem a valorização do papel ativo do aluno na (re)construção do saber, com espírito crítico e criativo. 
Perfil do Aluno e Aprendizagens Essenciais nas planificações curriculares - componentes do currículo visto pelos formandos

Palavras-chave: Currículo, Perfil do Aluno, Aprendizagens Essenciais, Autonomia

\section{Introdução}

O presente artigo resulta da aplicação de uma questão diagnóstico, aos formandos que se inscreveram e frequentaram a oficina de formação intitulada: "Perfil do Aluno e Aprendizagens Essenciais nas planificações curriculares" no ano letivo 2019/2020. A questão foi passada logo no início da primeira sessão de trabalho e antes de se abordar qualquer conteúdo, com o intuito de perceber as conceções dos formandos/docentes sobre o conceito de currículo. $\mathrm{O}$ conceito de currículo é um conceito basilar e estrutural de qualquer sistema educativo e, portanto, importava conhecer quais as componentes do conceito de currículo que os formandos incluíam com maior ou menor frequência.

No presente artigo damos conta das principais alterações curriculares vigentes no Sistema Educativo Português, apresentado-se uma breve sistematização do conceito do currículo, a metodologia, a apresentação e discussão dos resultados e, por fim, as considerações finais.

No presente artigo, dá-se conta que perante as alterações operadas no sistema educativo portugués, o entendimento que os formandos têm de currículo não se coaduna com o papel ativo do aluno na (re)construção do saber, com espírito crítico e criativo.

\section{Proliferação de documentos curriculares (des)norteadores}

Em Portugal, nas últimas décadas temos assistido à proliferação de documentos de orientação curricular, que coexistem, no mesmo tempo e espaço, por vezes com linhas estruturais pouco consentâneas, explícitas e inequívocas entre os mesmos.

Na sequência da publicação desenfreada de documentos, a comunidade docente no geral sente-se perdida dada a ausência de fio condutor entre os programas curriculares das diferentes disciplinas, bem como a sua extensão, manifestando dificuldades na articulação dos mesmos ao nível das planificações curriculares. Assim, surgiu um Referencial Curricular - Decreto-Lei n. ${ }^{\circ}$ 55/2018 de 6 de julho - corporizado pelo Perfil do Aluno à saída da escolaridade obrigatória (PA) e as Aprendizagens Essenciais (AE).

\subsection{Decreto-Lei n. ${ }^{\circ}$ 55/2018 - aparecimento e propósito.}

O normativo legal, Decreto-Lei n. ${ }^{\circ}$ 55/2018 publicado a 6 de julho de 2018, surgiu na sequência da proliferação de diversos documentos curriculares e da necessidade de garantir a igualdade de acesso à escola pública, promovendo o sucesso educativo e, por essa via, a 
igualdade de oportunidades, propósitos já constante da Lei de Bases do Sistema Educativo Português desde 1986 (LBSE), mas reforçados no presente diploma.

$\mathrm{Na}$ origem do referido diploma estiveram, de acordo com Trindade (2018), entre outros documentos: o Perfil dos alunos à saída da escolaridade obrigatória; as Aprendizagens Essenciais, que visam dar resposta à extensão dos programas curriculares; a definição da Estratégia Nacional de Educação para a Cidadania; a publicação do Decreto-Lei n. ${ }^{\circ}$ 54/2018 onde se configura o novo regime jurídico da Educação Inclusiva na Educação Préescolar e nos Ensinos Básico e Secundário; a divulgação das novas Orientações Curriculares da Educação Pré-escolar; e, o desenvolvimento do Programa Nacional de Promoção do Sucesso Escolar (PNPSE).

Neste sentido, o presente normativo legal corporiza o projeto que conduz as escolas e os professores não só a assumirem decisões curriculares, mas também a investirem noutros modos de organizar espaços e os tempos de trabalho, bem como a possibilidade de proporem um outro tipo de atividades e estratégias que estimulem: a inteligência, a autonomia, e, a participação dos alunos na gestão do quotidiano.

Um dos princípios subjacentes ao Decreto-Lei n. ${ }^{\circ}$ 55/2018 consiste, de acordo com o artigo $4 .^{\circ}$ alínea f), na promoção de maior articulação entre os três ciclos do ensino básico e o ensino secundário, assumindo uma gestão integrada, articulada e sequencialmente progressiva do currículo, isto é, assume-se a necessária verticalidade do currículo, por um lado. Por outro lado, a articulação horizontal permite promover conexões interdisciplinares ao nível da aquisição de conhecimentos e do desenvolvimento de competências dos domínios procedimental e atitudinal: valorização da gestão e lecionação interdisciplinar e articulada do currículo, através do desenvolvimento de projetos que aglutinem aprendizagens das diferentes disciplinas, planeados, realizados e avaliados pelo conjunto dos professores do conselho de turma ou do ano de escolaridade (art. $\left.4 .^{\circ}, \mathrm{i}\right)$ ).

\subsubsection{Perfil do Alunos à Saída da escolaridade Obrigatória}

Após um amplo debate nacional que envolveu professores, académicos, famílias, parceiros sociais e alunos, foi aprovado o Perfil dos Alunos à Saída da Escolaridade Obrigatória (PA), que estabelece a matriz de princípios, valores e áreas de competências a que deve obedecer o desenvolvimento do currículo. O PA é, portanto, o documento que permite regular o trabalho educativo a desenvolver ao longo dos anos em que os alunos deverão permanecer nas escolas, tendo sido construído de forma concertada com os desafios da sociedade e com um forte cunho inclusivo.

Neste sentido, o PA constitui-se como o documento de referência a nível curricular para os diferentes decisores e atores educativos, no que às decisões curriculares a adotar diz respeito. É, portanto, a matriz comum para todas as escolas e ofertas formativas no âmbito 
Perfil do Aluno e Aprendizagens Essenciais nas planificações curriculares - componentes do currículo visto pelos formandos

da escolaridade obrigatória, no que diz respeito: a nível curricular, ao planeamento, à realização, e, à avaliação interna e externa da aprendizagem.

\subsubsection{Aprendizagens Essenciais}

De acordo com a Direção Geral da Educação (DGE), as Aprendizagens Essenciais (AE) são documentos de orientação curricular base, por disciplina, na planificação, realização e avaliação do ensino e da aprendizagem, que visam conduzir ao desenvolvimento das competências inscritas no PA.

Nas AE, procurou-se, então, sistematizar, disciplina a disciplina e ano a ano, o conjunto essencial de conteúdos, capacidades e atitudes, que visam alcançar os seguintes objetivos:

a. Consolidar aprendizagens de forma efetiva;

b. Desenvolver competências que requerem mais tempo (realização de trabalhos que envolvem pesquisa, análise, debate e reflexão);

c. Permitir a diferenciação pedagógica na sala de aula (DGE https://www.dge.mec.pt/aprendizagens-essenciais).

Neste sentido, as AE são outro dos documentos de apoio às decisões curriculares dos professores que visa favorecer a autonomia do processo e potenciar a flexibilização das mesmas.

As AE encontram-se organizadas para cada uma das disciplinas que compõem as matrizes curriculares dos diferentes anos de escolaridade, organizado em função de uma: a) apresentação que contém os objetivos do trabalho a realizar numa disciplina, o seu contributo para formação dos alunos, as ideias e os seus conceitos nucleares, articulados com o PA; b) proposta de organização na qual, para cada um dos domínios em que se encontra organizada a disciplina, se explicitam:

(i) os descritores pormenorizados que dizem respeito aos conhecimentos, capacidades e atitudes que orientam as aprendizagens dos alunos;

(ii) as ações e estratégias de ensino a desenvolver para que estas aprendizagens possam ocorrer; e

(iii) as competências, previstas no PA que o trabalho deve favorecer.

Nesta ordem de ideias, podemos afirmar que as AE são o denominador curricular comum para todos os alunos, são a base comum de referência, permitindo libertar espaço curricular para que, em cada escola, se possa promover trabalho articulado entre as AE e as outras aprendizagens previstas nos demais documentos curriculares, com aprofundamento de temas, explorações interdisciplinares diversificadas, mobilização de componentes locais do currículo, entre outras opções, no âmbito dos domínios de autonomia curricular (DGE, https://www.dge.mec.pt/aprendizagens-essenciais). 


\subsection{Currículo - conceito}

Currículo é um conceito polissémico, pelo que cada um terá sempre a sua interpretação no que às componentes e desenvolvimento do currículo diz respeito (Pacheco, 1996; Ribeiro, 1999). Contudo, quando tentamos definir currículo com base nos aspetos que se mantêm ao longo do tempo, tendo em consideração o quadro histórico-cultural da relação da escola com a sociedade, ressalta que currículo escolar é - em qualquer circunstância - o conjunto de aprendizagens que, por se considerarem socialmente necessárias num dado tempo e contexto, cabe à escola garantir e organizar (Roldão e Almeida, 2018, p. 7).

Na tentativa de esclarecer o conceito de currículo, Ribeiro (1999) procedeu à análise de algumas aceções correntes e de aceções típicas sobre currículo de onde ressaltou a sistematização que se segue:

\begin{tabular}{|l|l|}
\hline $\begin{array}{l}\text { Com mais } \\
\text { frequência }\end{array}$ & $\begin{array}{l}\text { O QUE SE ENTENDE POR CURRÍCULO } \\
\text { - Lista de disciplinas/matérias de ensino (e respetivos tempos letivos atribuídos) } \\
\text { - Lista e/ou esquema de conteúdos programáticos } \\
\text { - Sequência organizada de conteúdos de ensino (o que se ensina) } \\
\text { - Série de objetivos de ensino (para que se ensina) } \\
\text { - Manuais e materiais didáticos (para o professor e/ou aluno) (com que se ensina) } \\
\text { - Métodos e processos de ensino (como se ensina) } \\
\text { - Conjunto de experiências/atividades na escola } \\
\begin{array}{l}\text { Com menos } \\
\text { frequência }\end{array}\end{array}$ \\
$\begin{array}{l}\text { Diferentes combinações das componentes anteriores ou, até, esse conjunto de } \\
\text { componentes }\end{array}$
\end{tabular}

Fig. 1 Figure

Fonte: Ribeiro(1999: 16)

De acordo com Roldão e Almeida (2018, p. 30), “O currículo - de um país, de uma escola, de uma turma - corporiza a opção organizativa e metodológica que se faz, num dado contexto, tempo e circunstância, para conseguir as aprendizagens pretendidas. $\mathrm{O}$ currículo assume assim um duplo significado - é, por um lado, o corpo de aprendizagens que se quer fazer adquirir e é também o modo, o caminho, a organização, a metodologia que se põe em marcha para o conseguir".

Neste sentido, a conceção de currículo como conjunto de experiências educativas engloba todas as atividades de aprendizagem proporcionadas na escola, quer elas resultem de intenções ou propósitos explícitos quer decorram da própria organização e ingredientes da vida escolar na sua multiplicidade. 
Perfil do Aluno e Aprendizagens Essenciais nas planificações curriculares - componentes do currículo visto pelos formandos

Perante mudanças tão profundas como aquelas que demos conta anteriormente, tal como referem Morgado e Silva (2019, p. 135) "torna-se inevitável adotar um novo conceito de currículo (...) mais centrado em quem aprende e não tanto em quem ensina" o que implica que seja entendido "como cultura real que surge de uma série de processos, mais do que um objeto delimitado e estático que se pode planear e depois implementar" (2019, p.136).

\section{Metodologia}

O presente estudo de caso incluiu a aplicação de uma questão diagnóstico, antes de qualquer abordagem téorica, composta por sete afirmações que os formandos tinham de ordenar tendo em conta aquilo que na sua ótica consideram ser, mais frequentemente, como currículo e que, portanto, se aproxima mais do seu entendimento/conceito de currículo. Assim, um correspondia à melhor aproximação e sete correspondia àquela que mais se afastava do seu entendimento/conceito de currículo. Participaram os 15 formandos que estavam inscritos na oficina de formação no ano letivo de 2019/2020, com cerca de 20 anos de serviço.

A informação recolhida foi analisada recorrendo-se para o efeito ao tratamento estatístico e a comparação com o entendimento dos formandos com a sistematização apresentada por Ribeiro (1999) nos anos 90 do século XX, na sua obra Desenvolvimento Curricular, relativamente a algumas componentes que se incluem com maior ou menor frequência no conceito de currículo.

\section{Análise e discussão dos dados}

Ao analisarmos as respostas dos formandos verificou-se uma grande dispersão de respostas face ao entendimento relativamente às componentes do currículo.

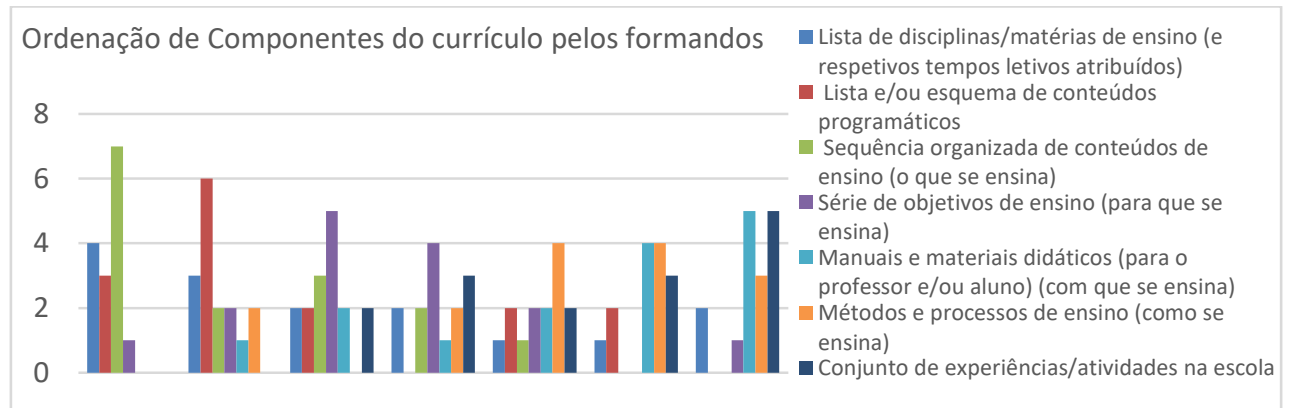

Fig. 1 Entendimento de currículo pelos formandos 
Assim, ao analisar as ordenações por afirmação destes formandos, no que concerne à maior aproximação do seu conceito de currículo, verificou-se que para sete dos respondentes a primeira componente do currículo era: sequência organizada de conteúdos de ensino (o que se ensina); a segunda componente com seis respostas foi lista e/ou esquema de conteúdos programáticos; e, por fim, cinco dos formandos selecionaram a série de objetivos de ensino (para que se ensina) como sendo aquela que mais se aproxima do seu conceito de currículo.

No que diz respeito às afirmações que mais se afastam do seu conceito de currículo verificou-se, com cinco respostas cada, as seguintes: manuais e materiais didáticos (para o professor e/ou aluno) (com que se ensina) e conjunto de experiências/atividades na escola.

No sentido de tornar mais visível o entendimento/aproximação do conceito de currículo pelos formandos/respondentes, optou-se por: adicionar as frequências obtidas para os valores de um a três (por serem os valores que representam a maior proximidade com o conceito de currículo) denominando-se por Próximo; manter isolado o nível quatro por ser o valor médio da escala, tendo-se designado por Indiferente; e, adicionar as frequências obtidas para os valores de cinco a sete (por serem valores que representam o maior afastamento relativamente ao conceito de currículo) designando-se por Afastado.

Assim, tornou-se mais explícito o entendimento do grupo de formandos relativamente ao que mais frequente e menos frequentemente entendem por currículo, respetivamente.

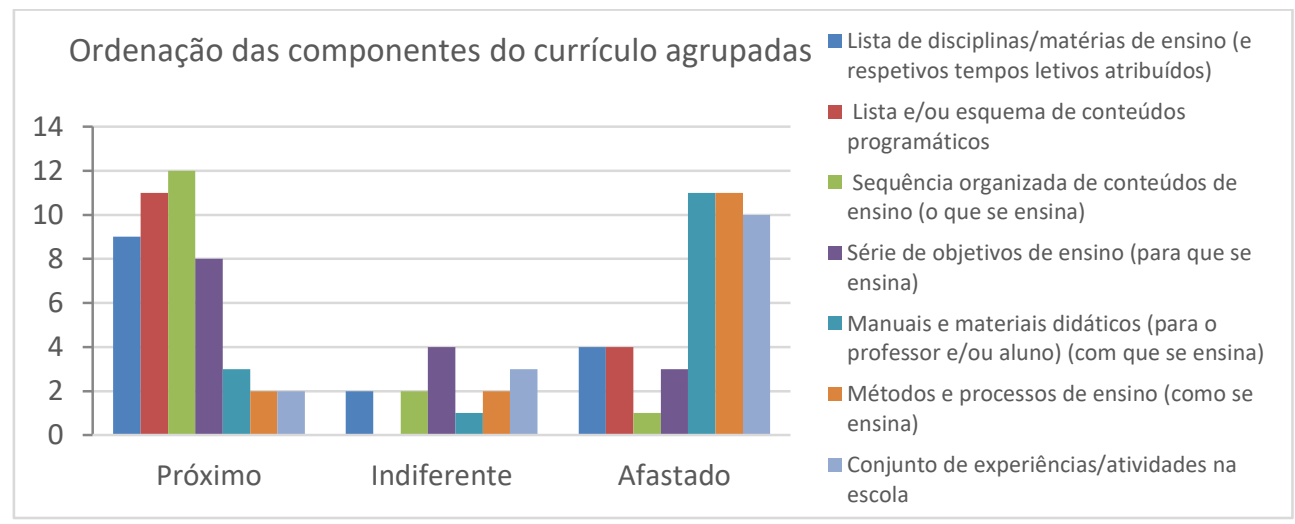

Fig. 2 Entendimento do currículo pelos formandos de forma agrupada.

Perante este reagrupamento das respostas tornou-se visível que os formandos respondentes entendem com maior frequência que o currículo corresponde: sequência organizada de conteúdos de ensino (o que se ensina), seguida de lista e/ou esquema de conteúdos programáticos e, por fim, lista de disciplinas/matérias de ensino (e respetivos tempos letivos atribuídos). No que concerne às afirmações que mais se afastam do seu entendimento de currículo verificou-se: manuais e materiais didáticos (para o professor e/ou 
Perfil do Aluno e Aprendizagens Essenciais nas planificações curriculares - componentes do currículo visto pelos formandos

aluno) (com que se ensina) e métodos e processos de ensino (como se ensina) com o mesmo número de respostas (11); e, por fim, conjunto de experiências/atividades na escola.

Ao comparar estes resultados com a sistematização apresentada com Ribeiro (1999) verificou-se existir uma concordância quer na maior quer na menor frequência do entendimento de currículo.

Perante as mudanças ocorridas em Portugal, desde 2017, não deixa de ser curioso a perpetuação de uma visão de currículo mais centrada no professor do que no aluno (Morgado e Silva, 2019), incompatível com adoção de práticas dinâmicas, promotoras de competências que requerem mais tempo (realização de trabalhos que envolvem pesquisa, análise, debate e reflexão) (DGE).

\section{Considerações Finais}

Com este estudo de caso, percebeu-se que este grupo de formandos vê ainda o currículo como um conjunto de saberes acabados e universais a transmitir a todos, sem que exista a valorização do papel ativo do aluno na (re)construção do saber, com espírito crítico e criativo.

Muito provavelmente, esta constatação deve-se ao facto de ser um grupo de formandos com mais de 20 anos de serviço, que foi formado numa lógica bem diferente da atual, onde se valorizava a memorização e a passividade do aluno e que tendencialmente tendem a reproduzir o mesmo ensino que receberam, até por uma questão securizante.

Um longo caminho há a percorrer, onde a formação contínua tem um papel preponderante na alteração de práticas, servindo de rede de suporte e proteção aos professores em exercício.

\section{Referências}

Cohen, A. C., \& Fradique, J. (2018). Guia da Autonomia e Flexibilidade Curricular. Lisboa: Raiz Editora.

DGE (2018). Aprendizagens Essenciais. Consultado a 24 de maio de 2020 https://www.dge.mec.pt/aprendizagens-essenciais

ME. (2017). Perfil dos alunos à saída da Escolaridade Obrigatória, Lisboa: Editorial do ME e Ciência.

Morgado, J. C., \& Silva, C. (2019). Articulação Currcular e Inovação educativa: caminhos para a flexibilidade e autonomia. in Morgado, J.C., Viana, I.C., Pacheco, J.A. (org).Currículo, Inovação e Flexibilização. Santo Tirso: De Facto editores, pp.129-148.

Ribeiro, A. C. (1999). Desenvolvimento Curricular. Lisboa: Texto Editora. 
Roldão, M. ${ }^{a}$ C., \& Almeida, S. (2018). Gestão Curricular para a autonomia das escolas e professores. Lisboa:DGE.

Trindade, R. (coord.) (2018). Autonomia, flexibilidade e gestão curricular: relatos de práticas, Lisboa: Leya Educação.

\section{Legislação}

Decreto-Lei n. ${ }^{\circ}$ 54/2018 publicado a 6 de julho de 2018.

Decreto-Lei n. ${ }^{\circ} 55 / 2018$ publicado a 6 de julho de 2018. 